\title{
Processos de transição para a vida activa e profissional nas universidades de Sofala (Moçambique)
}

\author{
Júlio Taimira Chibemo* e Fernando Canastra** \\ *Instituto Superior de Ciências e Tecnologia Alberto Chipande \\ **Universidade Católica de Moçambique
}

\begin{abstract}
Resumo
O presente trabalho tem como objectivo central procurar investigar o processo de transição dos estudantes para a vida activa e profissional nas universidades de Sofala, em Moçambique. Neste contexto, o processo de transição para a vida activa e profissional assume uma relevância significativa, considerando, por um lado, as incertezas, a precaridade e a mobilidade permanente no campo da empregabilidade, devido, entre outras razões, à globalização de matriz neoliberal; por outro lado, a competitividade, no mercado de trabalho, gera novas exigências e necessidades, em termos de dinâmicas autoformativas e da necessidade de aprendizagem ao longo da vida. Contudo, hoje, pede-se algo mais, quando falamos de "transição para a vida activa e profissional", isto é, mais do que acompanhar uma "passagem", tratase, cada vez mais, de acompanhar e mediar um "percurso" no quadro das trajectórias de vida, tendo em conta a vida profissional futura. É, neste contexto, que se inscreve este estudo, procurando dar respostas a este fenómeno, no âmbito das Instituições do Ensino Superior em Sofala (Moçambique). Assim, o estudo procura dar conta das diversas experiências que existem neste contexto, tendo como metodologia privilegiada a investigação participativa, uma vez que procuramos não só identificar as dificuldades existentes, mas apresentar propostas de melhoria.
\end{abstract}

Palavras-Chave: Transição, Vida Activa, Vida Profissional, Experiências de Transição.

Abstract
The present work aims to search for central
investigating the students ' transition to working life and
professional at the universities of Sofala Province in
Mozambique. In this context, the process of transition to
the active and professional life takes a significant
relevance, considering, on the one hand, the
uncertainties, precariousness and permanent mobility in
the field of employability, due, among other reasons, to
the globalization neoliberal matrix; on the other hand,
the competitiveness in the labour market, generates new
demands and requirements, in terms of self-training
dynamics and the need for lifelong learning. However,
today, we need to do something more, when we speak of
"transition to working life and professional", i.e. more
than accompany a "passage", that is, increasingly, to

monitor and mediate a "route" in the context of the life trajectories, taking into account the future professional life. It is in this context that subscribes this study, trying to give answers to this phenomenon, within the framework of the institutions of higher education in Sofala (Mozambique). Thus, the study seeks to give an account of the various experiences that exist in this context, having privileged participatory research methodology, since we not only identify the existing difficulties, but to make proposals for improvement.

Keywords: Transition, Working Life, Professional Life, Transition Experiences.

\section{Introdução}

O processo de transição para a vida activa inscreve-se numa dinâmica, cada vez mais, flutuante e contínua. As "transições", que era suposto serem "fases" situadas no tempo, hoje em dia, tendem a prolongar-se ao longo das trajectórias de vida, quer enquanto estudantes, quer como profissionais (Boutinet, 2000).

Neste contexto, importa reflectir sobre as implicações desta mudança constante, em termos de necessidade de adaptação contínua aos contextos de vida e aos percursos profissionais. $\mathrm{O}$ ensino superior não fica à margem deste processo, pois, tanto em termos de transição do ensino secundário, para o ensino superior, como deste para a vida activa ou o mercado de trabalho, tem que dar uma resposta a esta problemática (Matias, 2014; Sitóe, 2014).

A orientação vocacional e profissional, no contexto do ensino superior, torna-se numa ferramenta fundamental para que a universidade desempenhe, de forma responsável e proveitosa, o seu papel no quadro dos processos de transição dos estudantes para a vida activa e profissional ou para o mercado do trabalho, de modo a responder às demandas e às exigências da sociedade actual que tende a tornar-se, cada vez mais, global.

Num contexto de globalização e constante interdependência, onde os ideais do neoliberalismo se expandem, um pouco por toda a parte, urge repensar o papel da universidade enquanto agência de conhecimento, mas como promotora de inclusão (coesão) social e profissional. As dinâmicas emergentes de "emprego precário" e a mobilidade 
permanente no campo da empregabilidade geram novas formas de vulnerabilidade social e profissional (Gennari, \& Albuquerque, 2012).

O presente estudo, realizado na Província de Sofala (Moçambique), no contexto do ensino superior procura perceber como é que as instituições do ensino superior enfrentam estas preocupações e necessidades, no quadro dos processos de transição, dos futuros profissionais, entre a universidade, a sociedade e o mercado de trabalho.

Considerando a falta de estudos, dentro desta problemática, particularmente no contexto moçambicano, este estudo mostra algumas das implicações que emergem neste contexto, onde se assiste a uma proliferação de instituições de ensino superior. Todavia, importa questionar até que ponto este aumento quantitativo tende a ser acompanhado por uma real preocupação com os processos de transição dos estudantes e futuros profissionais, num contexto social e profissional marcado pela precariedade laboral, mobilidade constante e adaptação permanente.

\section{Um breve olhar sociológico sobre as dinâmicas de empregabilidade}

O retrato social dos Jovens, de hoje, indica que esta faixa etária vive num contexto diferente daquele que se caracterizava, no séc. XX, onde ainda se podia sonhar com um "emprego estável" e, nalguns casos, uma "emprego para toda a vida" (Tomás-Agulló, 1997; Costa, 1996; Sanchis, 1997).

No séc. XXI, uma das mudanças mais significativas que se operaram está relacionada com a crescente globalização, à escala planetária, criando novas dinâmicas de sociabilidade e de empregabilidade. Os grandes grupos económicos deslocam-se para países, onde a mão-de-obra é pouco qualificada, dando origem a fenómenos de precariedade, nunca antes visto, particularmente na população mais jovem. Acresce que esta situação agrava-se, pelo facto de, cada vez mais, os jovens, embora tenham um nível alto de qualificação, deparamse, logo à saída da universidade, com o "desemprego prolongado" ou, então com "empregos precários", de baixo custo salarial, não valorizando o conhecimento adquirido e as competências desenvolvidas, no quadro de uma formação de nível superior (Campos, 2013; Peres, Silva, \& Carvalho, 2003).

Esta dinâmica de flexibilização laboral e mobilidade geográfica tem vindo a gerar fenómenos, cada vez mais crescentes, de vulnerabilidade social e de fragilização das solidariedades identitárias que, durante muito tempo, funcionavam como o cimento das identidades pessoais, sociais e profissionais (Campos, 2013; Castel, 1995; Silva, 2007).

Estas "novas formas de trabalho", profundamente marcadas por lógicas de flexibilização do mercado e de precariedade do emprego colocam perante novos desafios, particularmente ao nível da crescente desigualdade social. Na realidade, o "trabalho precário/trabalho flexível" tende a impor-se, de forma global, e, ainda que, como preconiza a filosofia marcadamente neoliberal, esta reconfiguração gera mais crescimento económico, mas traz consequências nefastas em termos de justiça social, afastando muitos daquilo que deveria ser uma "sociedade de oportunidades" (Dubet, 2010; Sá, 2010; Wilkinson \& Pickett, 2010).

É neste contexto social e laboral que se deve equacionar a questão das "transições", entre a universidade, a sociedade e o mercado de trabalho.

\section{Transições Permanentes versus Instituições de Ensino}

Os processos de transição, hoje, tendem a inscrever-se numa alternância de períodos curtos de trabalho e de não-trabalho ao longo da vida, implicando, deste modo, novas formas de transição entre "escola/formação, trabalho/desemprego, casamento/divórcio” (Sá, 2010, p. 9).

Por isso, hoje se fala de "transições" ao longo da vida e não apenas reportadas a certas fases da vida (Matias, 2014). Neste sentido, importa clarificar qual deve ser o papel das instituições de ensino, em geral, e, no caso em apreço, do ensino superior.

É neste contexto que ganha relevância a ideia de que "a orientação universitária" deve recentrar-se no projecto de vida e profissional dos estudantes e futuros profissionais (Boutinet, 2000; García, 2002; Rodriguez Moreno, 2002). O conceito de "orientação universitária" procura convocar uma abordagem mais integradora e complexa do que se entende, hoje, por orientação vocacional e profissional. Na realidade, o desafio que se coloca às universidades é o de promoverem serviços de orientação integrados e que incidam no desenvolvimento de competências para aprender a aprender ao longo da vida (Delors, 1996).

As universidades devem preparar os estudantes, tendo em conta o seu futuro profissional para desenvolverem as suas capacidades e competências, investindo, particularmente, naquelas que assumem um carácter transversal, como as centradas no aprender a aprender, saber trabalhar em equipa, dominar as tecnologias de informação e comunicação, competências sociais e cívicas, espírito de iniciativa e de empreendedorismo, capacidade de adaptabilidade contextual e ecológica (Le Boterf, 2003; Perrenoud, 2007).

Outro papel fundamental das universidades e instituições de ensino superior é a de se tornar uma agência de mediação. Para Casals, Masjuan e Planas (1989), como mediadoras entre o período de formação e a fase profissional, as universidades podem actuar tendo em conta "o itinerário de formação, a transição do mundo educacional para o mundo do trabalho, o itinerário do trabalho e a autonomia familiar; a transição pode se processar antes da graduação, no caso de o universitário (estudante-trabalhador ou trabalhador-estudante) manter um contacto formalizado com o mercado de trabalho" (Casals, Masjuan \& Planas, 1989, p.12)

Por conseguinte, o principal desafio, que enfrentam as instituições do ensino superior, hoje em 
dia, prende-se com a necessidade de promover "novas formas de mediação" no quadro dos processos de transição dos estudantes e futuros profissionais. Neste sentido, o papel da "orientação universitária" ganha relevo e importância, particularmente no contexto moçambicano, onde, efectivamente, é quase inexistente. $\mathrm{O}$ presente estudo mostra a tendência que se verifica num conjunto de instituições de ensino superior, na Província de Sofala (Moçambique), no que diz respeito ao modo com estas instituições respondem aos desafios traçados, brevemente, nesta primeira secção do nosso artigo.

\section{Método}

O estudo que, agora é apresentado, procura dar conta do processo de transição para a vida activa e profissional nas universidades da Província de Sofala, em Moçambique. Numa primeira aproximação "ao terreno", constatou-se que neste campo, as universidades e instituições de ensino superior estão a dar os seus primeiros passos. Logo, os resultados que são apresentados revestem-se de um carácter exploratório, não havendo ainda dados recolhidos e sistematizados.

Partindo do pressuposto de que a temática em estudo, sobretudo em Sofala, em particular, e em Moçambique, no geral, ainda não reúne dados sistemáticos, optou-se por uma pesquisa exploratória e um Estudo de Caso (Flick, 2005). Esta metodologia permitiu ter acesso aos contextos naturais para perceber, in loco, a complexidade de um fenómeno. A opção por um estudo de caso, na Província de Sofala, justifica-se pelo facto de termos várias instituições do ensino superior. Com esta opção metodológica foi possível aprofundar esta temática, considerando a escassez de dados empíricos. Assim, na primeira fase deste estudo, decidimos entrevistar os responsáveis das instituições do ensino superior, neste contexto geográfico, de modo a percebermos o que efectivamente se está a fazer neste campo relacionado com a orientação vocacional e profissional.

\section{Participantes}

Participaram, neste estudo exploratório, as seguintes instituições: Universidade Pedagógica, Universidade Católica, Universidade Zambeze, Universidade Jean Piaget e o Instituto Superior de Ciências e Tecnologia Alberto Chipande. Numa primeira aproximação, optou-se por inquirir os responsáveis das instituições ou seus representantes, pelo facto de estarmos a dar início ao estudo que, numa fase posterior, irá inquirir, também, outros actores (como, por exemplo, os docentes e estudantes).

\section{Instrumentos e procedimentos}

A principal técnica usada, para recolha dos dados empíricos, foi a administração de inquéritos e o recurso a entrevista semi-estruturada (Flick, 2005). Este tipo de entrevista permite que se use um guião com algumas questões formuladas previamente, ainda que, no momento da sua realização, haja espaço para acomodar as mesmas ao ritmo dos entrevistados. Pretende-se, ainda, nesta fase, explorar e aprofundar o papel da orientação vocacional e profissional no contexto das instituições do ensino superior, na Província de Sofala. Posteriormente, com base na análise dos resultados exploratórios, construiu-se e aplicou-se um Inquérito por Questionário dirigido aos estudantes das diversas instituições que são objecto deste estudo. Por sua vez, ao nível dos docentes, de no sentido de problematizar este campo de intervenção, iremos recorrer à técnica de Discussão de Grupos (Flick, 2005; Sampieri, Collado \& Lucio, 2006).

\section{Apresentação e Discussão dos Resultados}

$\mathrm{O}$ estudo foi realizado em cinco instituições de ensino superior que operam na Cidade da Beira, Província de Sofala, em Moçambique, onde os inquéritos foram administrados a estudantes estagiários e a responsáveis das instituições que lidam com a questão dos estágios profissionais dos seus graduandos. Os dados recolhidos ao longo do estudo foram sistematizados com ajuda do programa informático conhecido por "CSPro", enquanto o processamento e tabulação foi efectuado através do programa estatístico "SPSS for Windows". Desta feita, o estudo apresenta indicadores quantitativos e qualitativos, através de tabelas e gráficos. Esses dados procuram dar conta das percepções e acções dos inqueridos, nas instituições de ensino superior que operam na Cidade da Beira. Portanto, a leitura e cruzamento dos dados foram feitos tendo em conta a percentagem dos indicadores.

\section{Percepção dos Estagiários}

O estudo abarcou 390 casos de estudantes estagiários da Universidade pedagógica, UNIZAMBEZE, Universidade Católica de Moçambique, UNPIAGET e Instituto Superior de Ciências e Tecnologia Alberto Chipande. Deste universo, a maioria dos casos são da Universidade Católica, com $22.3 \%$, contra $19.2 \%$ do ISCTAC, $19.2 \%$ da Universidade Pedagógica, $19.7 \%$ da UNIZAMBEZE e $19.2 \%$ da UNIPIAGET. Grande parte dos estudantes efectuou seus estágios nas escolas primárias e secundárias, bem como no Hospital Central da Beira, conforme mostram os dados na tabela, abaixo.

\section{Tabela 1: Estagiário na Empresa}

Instituições/Empresa Casos Percentagem de Estágio

\begin{tabular}{lcc}
\hline $\begin{array}{l}\text { Direcção Provincial } \\
\text { das Finanças }\end{array}$ & 11 & $2.8 \%$ \\
$\begin{array}{l}\text { Hospital Central da } \\
\text { Beira }\end{array}$ & 139 & $35.6 \%$ \\
$\begin{array}{l}\text { Indico Companhia de } \\
\text { Seguros }\end{array}$ & 18 & $4.6 \%$ \\
FIPAG & 16 & $4.1 \%$ \\
Young Africa & 10 & $2.6 \%$ \\
Escola Secundaria & 6 & $1.5 \%$ \\
Samora Machel & & \\
Escola Secundaria da & 9 & $2.3 \%$
\end{tabular}




\begin{tabular}{lrr} 
Manga & & \\
Escola Secundaria do & 12 & $3.1 \%$ \\
Estoril & & \\
Escola N. Senhora da & 10 & $2.6 \%$ \\
Fátima & & \\
Escola da Catedral & 9 & $2.3 \%$ \\
Instituto Nacional de & 24 & $6.2 \%$ \\
Segurança Social & & \\
Escola Secundaria da & 3 & $0.8 \%$ \\
Munhava & & \\
Escola Secundaria & 13 & $3.3 \%$ \\
Estrela da Manha & & \\
Escola Secundaria & 13 & $3.3 \%$ \\
American Board & & \\
Sem resposta & 5 & $1.3 \%$ \\
EDM & 16 & $4.1 \%$ \\
EMOSE & 23 & $5.9 \%$ \\
Autoridade & 20 & $5.1 \%$ \\
Tributaria & & \\
Tribunal & 13 & $3.3 \%$ \\
IPAJ & 9 & $2.3 \%$ \\
CDM & 11 & $2.8 \%$ \\
& 390 & $100 \%$ \\
\hline
\end{tabular}

Do universo dos inqueridos, grosso modo estagiou em escolas secundárias que operam na Cidade da Beira, sejam elas públicas e privas. Todavia, em termos gerais, a Companhia Hidroelétrica de Cahora Bassa encontra-se na dianteira com $35.6 \%$, seguida do INSS (6.2\%), a Empresa Moçambicana de Seguros (5.9\%) e a Autoridade Tributária de Moçambique $(5.1 \%)$. O resto dos casos não ultrapassou a fasquia dos $5.0 \%$.

\section{Gráfico 1: Área de Formação dos Estagiários Entrevistados}

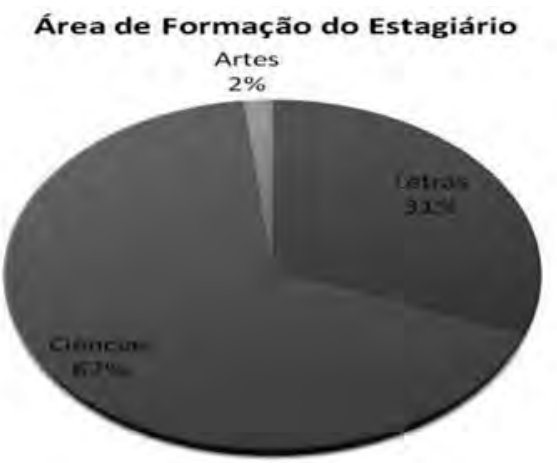

Do universo dos inqueridos, a maioria frequente cursos da área de Ciências Exactas (67.2\%), contra $31.0 \%$ que frequenta cursos de letras, enquanto apenas $1.8 \%$ frequenta cursos de belas artes. Os estudantes que se encontram a estagiar, uma maioria esmagadora $(90.5 \%)$ estão em instituições públicas, contra apenas $9.5 \%$ que se encontram em instituições privadas. Logo, os estágios são mais recebidos em instituições do Estado, do que as privadas. Quanto questionados sobre a relação entre a área em que se encontra a estagiar e a sua formação académica, $100 \%$ responderam que sim e obtiveram acesso ao estágio através da instituição de ensino, como demonstra a tabela, abaixo.
Tabela 2: Como teve acesso ao estágio profissional

\begin{tabular}{|c|c|c|}
\hline Respostas & Casos & Percentagem \\
\hline Através da & 203 & $52.1 \%$ \\
\hline Instituição de Ensino & & \\
\hline $\begin{array}{l}\text { Através de Meios } \\
\text { Próprios }\end{array}$ & 185 & $47.4 \%$ \\
\hline Sem Resposta & 2 & $0.5 \%$ \\
\hline Total & 390 & $100 \%$ \\
\hline
\end{tabular}

De acordo com os dados patentes na tabela, acima, pode-se notar que há um ligeiro equilíbrio em relação a forma como os inqueridos tiveram acesso ao estágio profissional. Desta feita, 52.1\% dos mesmos tiveram acesso ao estágio profissional através da instituição de ensino, contra $47.4 \%$ que tiveram acesso através de meios próprios, enquanto $0.5 \%$ não respondeu a pergunta.

Quando questionados sobre a possibilidade de ser convidado a permanecer na empresa como trabalhador efectivo, $43.1 \%$ respondeu que sim, contra $27.7 \%$ que respondeu que não tinha certeza e $29.0 \%$ respondeu que não, enquanto $0.3 \%$ não respondeu à pergunta. Em relação à justificação para a possibilidade de se tornar funcionário efectivo, depois do estágio, as respostas são dispersas, porque a maioria $(47.7 \%)$ não deu qualquer resposta, o que demonstra algum cepticismo. Todavia, $35.1 \%$ dos inqueridos apontou a natureza do concurso público, como elemento que determina a possibilidade dele aceitar a proposta para ser efectivo, contra $14.6 \%$ que apontou para a natureza do contrato da empresa. Por seu turno, $1.3 \%$ só aceitaria depois de ter terminado o estágio, enquanto outros $1.3 \%$ apontou que sempre há informação de que não há vagas, inibindo qualquer tentativa de se tornar funcionário efectivo da instituição onde realizou o seu estágio.

O gráfico, abaixo, apresenta as pecepções dos estagiários inqueridos sobre a classificação que davam ao estágio que praticaram. A maioria esmagadora classificou como bom, como demonstra o gráfico, abaixo.

\section{Gráfico 2: Classificaçãodo Estágio Profissional}

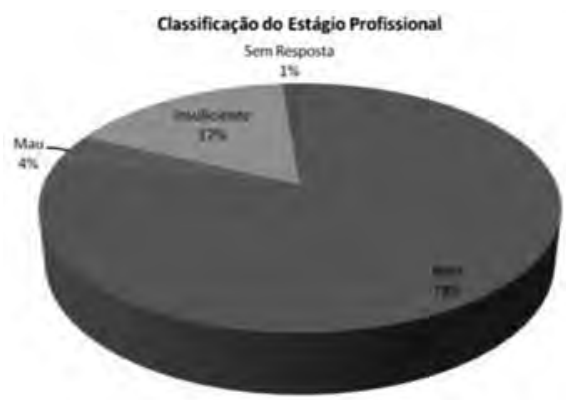

De acordo com os dados patentes no gráfico, acima, pode-se notar que a maioria dos inqueridos (77.9\%) classificaram o estágio profissional como sendo bom, contra apenas $4.1 \%$ que classificou como mau, enquanto $16.7 \%$ classificou como insuficiente e 
$1.3 \%$ não deu qualquer resposta. Neste contexto, ficase com a ideia de que para os estagiários, o estágio é um elemento importante na sua formação e preparação para vida activa e profissional. Uma das razões principais para a boa classificação do estágio profissional prende-se com a ideia de que o estágio profissional ajuda a melhorar as actividades na vida prática, como demonstra os dados patentes na tabela, abaixo.

Tabela 3: Justificação da classificação

\begin{tabular}{lcr} 
Respostas & Casos & Percentagem \\
\hline Tem & 59 & 15.1 \\
Acompanhamento & 68 & 17.4 \\
$\begin{array}{l}\text { Sem } \\
\text { Acompanhamento }\end{array}$ & 191 & 49.0 \\
$\begin{array}{l}\text { Ajudou-me a } \\
\text { Melhorar na Prática }\end{array}$ & 62 & 15.9 \\
$\begin{array}{l}\text { Sem Resposta } \\
\text { Omissão dos }\end{array}$ & 4 & 1.0 \\
$\begin{array}{l}\text { Conhecimentos } \\
\text { Curto Tempo de }\end{array}$ & 5 & 1.3 \\
$\begin{array}{l}\text { Estágio } \\
\text { Longo Tempo de } \\
\text { Duração do Estágio }\end{array}$ & 1 & 0.3 \\
$\quad$ Total & 390 & $100 \%$ \\
\hline
\end{tabular}

De acordo com os dados patentes na tabela, acima, pode-se notar que quando convidados a justificar a classificação feita em relação ao estágio profissional, $49.0 \%$ apontou que o estágio profissional ajuda a melhor a actividade prática; contra $0.3 \%$ que apontou para longo tempo de duração do estágio; por seu turno, $17.4 \%$ apontou para a falta de acompanhamento ao longo do estágio, contra $1.0 \%$ que referiu que há omissão de conhecimento por parte dos funcionários da instituição e $15.1 \%$ referiu que tem acompanhamento.

\section{Percepção das Instituições do Ensino Superior}

Abaixo, são apresentadas as percepções das instituições de ensino superior que operam em Sofala sobre o acompanhamento dos estudantes no seu processo de transição académica e profissional. No âmbito da recolha dos dados, todas as instituições (UP, UNIZAMBEZE, UNIPIAGET, Universidade Católica e Instituto Superior de Ciências e Tecnologia Alberto Chipande) participaram do estudo, através do responsável pelo sector da divisão académica ou o responsável pela coordenação dos estágios profissionais dos estudantes, ao longo da sua formação, porque para alguns cursos os estágios começam no segundo ano, enquanto para os outros o estágio profissional está reservado para o final do curso, no quarto ano ou depois de terminar as cadeiras, no período em que o estudante encontra-se a elaborar o seu trabalho de final decurso.

Em todas as instituições de ensino superior de Sofala, onde o estudo foi levado a cabo, nenhuma possui órgãos especializados ou responsáveis pela transição dos estudantes da vida estudantil, para a vida profissional. Tudo indica que esse processo é feito de forma ad hoc ou, pelas repartições pedagógicas ou ainda pela iniciativa dos estudantes. Há alguns casos, como o da Universidade Católica de Moçambique, mas o órgão ainda não se encontra em actividade e isso ocorreu em todas as outras instituições. Quando questionadas se possuem à disposição dos estudantes informação relevante e suficiente para a sua inserção no mercado de trabalho, a maioria referiu que não, como se pode constatar na tabela, abaixo.

Tabela 4: A IES Dispõem de Informação inserção

\begin{tabular}{|c|c|c|}
\hline Respostas & Casos & Percentagem \\
\hline $\operatorname{Sim}$ & 2 & $40.0 \%$ \\
\hline Não & 3 & $60.0 \%$ \\
\hline Total & 5 & $100 \%$ \\
\hline
\end{tabular}

De acordo com os dados patentes na tabela, acima, pode-se notar que $60.0 \%$ das instituições de ensino superior inqueridas, em Sofala, não dispõem de Informação relativa a inserção dos estudantes no mercado de trabalho. Todavia, todas elas afirmaram categoricamente que disponibilizam Supervisores para acompanhar os estagiários, ao longo da efectivação do seu estágio profissional e que culmina com a elaboração do relatório de estágio, que é avaliado e classificado.

\section{Gráfico 3: Tempo Previsto Para Conclusão do} Estágio

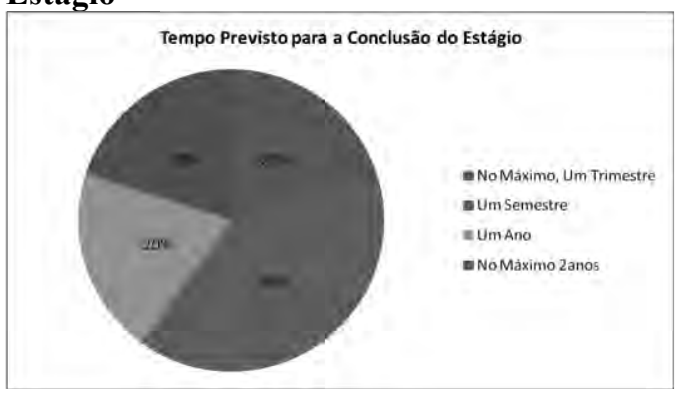

Quando questionadas sobre o tempo previsto para a conclusão do estágio, $40.0 \%$ referiu que o estágio profissional dura um semestre, contra os restantes que apontaram entre um trimestre, no máximo, um ano e dois anos, respectivamente. Neste contexto, todas as instituições afirmaram categoricamente que possuem acordos de inserção profissional dos seus formados com instituições públicas e privadas. Quando questionadas para dar exemplos, há um equilíbrio entre as instituições, como demonstra a tabela, abaixo.

\section{Tabela 5: Exemplos de acordos}

\begin{tabular}{lcr}
\multicolumn{1}{c}{ Instituições } & Casos & Percentagem \\
\hline $\begin{array}{l}\text { Todas Direcções } \\
\text { provinciais }\end{array}$ & 1 & $20.0 \%$ \\
IPAJ, HCB, & 1 & $20.0 \%$
\end{tabular}


Ministério de

Interior e Young

Africa

$\mathrm{HCB}, \mathrm{CFM}$,

1

$20.0 \%$

Açucareira de

Mafambisse,

Direcção das obras

Publicas, Direcção

Provincial da

Educação.

DPS, Cornelder

Moç, BIM, INSS

DPS, LDH

Tota

1

$20.0 \%$

$20.0 \%$

$100 \%$
De acordo com os dados patentes na tabela, acima, pode-se notar que as instituições de ensino superior inquerida, que operam em Sofala, têm acordos para inserção dos seus formados com o Instituto de Patrocínio e Assistência Jurídica - IPAJ, Hospital Central da Beira, Ministério de Interior e Young Africa, CFM, Açucareira de Mafambisse, Direcção das obras Publicas, Direcção Provincial da Educação, Direcção Provincial da Saúde, Cornelder Moç, Banco Millenium BIM, Instituto Nacional de Segurança Social e Liga Moçambicana dos Direitos Humanos.

\section{Considerações Finais}

O processo de transição dos estudantes, do ensino superior, para a vida activa e profissional, inscreve-se numa dinâmica, cada vez mais, flutuante e contínua, no contexto actual nacional, regional e global. Desta feita, a orientação vocacional e profissional nas instituições de ensino superior torna-se uma ferramenta fundamental para que a universidade desempenhe, de forma responsável e proveitosa, o seu papel no quadro dos processos de transição dos estudantes para o mercado do trabalho, como forma de responder positivamente às demandas e às exigências da sociedade actual e do mercado de emprego.

As universidades que operam na Província de Sofala mostram uma preocupação com os processos de transição dos seus estudantes, contudo, fica, também, patente que importa investir mais na sua capacidade de adaptação aos contextos de incerteza e de mudança em que vivemos. Neste sentido, as instituições poderão melhorar estas dinâmicas de transição, investindo em estruturas e redes de apoio à inserção profissional, como, por exemplo, através da criação de Observatórios Profissionais. Por outro lado, os curricula devem estar centrados numa lógica de desenvolvimento de competências, investindo, particularmente, naquelas que assumem um carácter transversal, uma vez que este tipo de competências podem preparar os estudantes para vivem em dinâmicas de incerteza e de precariedade laboral, exigindo uma adaptação permanente.

Constatou-se, ainda, que as instituições de ensino superior, que operam em Sofala, não dispõem de informação relativa ao processo de inserção dos estudantes no mercado de trabalho, o que mostra que a preocupação destas cessa, quando os estudantes concluem os seus cursos. É certo que, em todas elas, há uma preocupação pela vertente profissionalizante, promovendo diversas modalidades de estágio. Contudo, quando se trata do processo de transição entre universidade, sociedade e mercado de trabalho, nota-se que ainda há um longo trabalho a ser feito.

\section{Referências Bibliográficas}

Bardin, L. (2000), Análise de Conteúdo. Lisboa: Edições 70.

Boutinet, J. (2000). Imaturidade da Vida Adulta. Porto: Rés-Editora.

Castel, R. (1995). Les Métamorphoses de la question sociale. Paris: Gallimard.

Campos, A. (2013). Trabalho, Qualificação, Poder e Precariedade: Uma abordagem dinâmica à estruturação dos modelos produtivos, a partir de um estudo de caso da profissão científica.

Revista de Sociologia, 25.

http://www.scielo.gpeari.mctes.pt/scielo.php?pid $=\mathrm{S} 087234192013000100002 \&$ script $=$ sci_arttext

Costa, A. (1996), Protagonismo Juvenil: Adolescência, Educação e Participação Democrática. In Modus Faciendi, Desenvolvimento social e ação educativa. Minas Gerais: Fundação Odebrecht.

Fachin, Odília (2001), Fundamentos de Metodologia

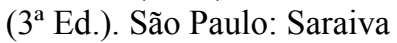

Flick, U. (2005). Métodos qualitativos na investigação científica. Lisboa: Monitor.

Gennari, A. \& Albuquerque, C. (2012). Globalização e reconfigurações do mercado de trabalho em Portugal e no Brasil.

http://www.scielo.br/scielo.php?pid=S01026909 $2012000200005 \&$ script $=$ sci arttext

Gustavo, V. \& Torini, D. (2014). Transições da Escola para o Mercado de Trabalho de Mulheres e Homens Jovens no Brasil. Programa de Emprego Jovem Departamento de Política de Emprego, Work4Youth Série de publicações No. 25, Genebra: Organização Internacional do Trabalho.

Le Boterf, G. (2003). Desenvolvendo a competência dos profissionais (3. Ed.). Porto Alegre: Artmed.

Margulis, M. (2001). Juventud: una aproximación conceptual. In S. Donas (Org.), Dolescencia y Juventud en América Latina. Cartago: Livro Universitário Regional, 2001. p. 41- 56.

Matias, J. (2014). Transição para a vida activa: estratégias de empregabilidade. Caminhos para construir transições mais inteligentes e mais humanas. Revista Electrónica de Investigação e Desenvolvimento, 3. http://reid.ucm.ac.mz/ index.php/reid/issue/view/5 .

Peres, R.; Silva, J. \& Carvalho, A. (2003). Um olhar psicológico acerca do desemprego e da precariedade das relações de trabalho. http://editorarevistas.mackenzie.br/index.php/pt p/article/view/1184.

Sá, T. (2010). "Precariedade" e "trabalho precário": consequências sociais e precarização laboral. 
Revista de Sociologia Configurações, 7. http://configuracoes.revues.org/203\#text.

Sampieri, H., Collado, C. \& Lucio, P. (2006). Metodologia de pesquisa ( $3^{\mathrm{a}}$ ed.). São Paulo: McGraw-Hill.

Sanchis, E. (1997). Da Escola ao Desemprego. Rio de Janeiro: Agir.

Sitóe, A. (2014). Transição do ensino secundário para o ensino superior - sugestão para uma abordagem psico-epistemológica. Revista Electrónica de Investigação e Desenvolvimento, 3. http:// reid.ucm.ac.mz/index.php/reid/issue/view/5.
Silva, M. (2007). Trabalho e Sindicalismo em Tempo de Globalização. Mafra (Portugal): Círculo de Leitores.

Tavares, V. (2009). Orientação Vocacional e Profissional: Um Estudo Sobre o Funcionamento das Estruturas de Orientação nas Escolas do Distrito de Braga. Granada: Editorial de la Universidade de Granda.

Tomás-Agulló, E. (1997). Jóvenes, Trabajo e Identidad. Oviedo: Universidade de Oviedo. 